\title{
DEVELOPMENT OF A MULTI PURPOSE AUTOMATED FARM EQUIPMENT
}

\section{K.V.P. CHAKRADHAR* $*$ T.VIJAYA BABU}

Faculty, Department of Mechanical Engineering, Vardhaman College of Engineering, Shamshabad, Hyderabad, India

\begin{abstract}
The aim of sustainable agriculture is production of high-quality produce and raw materials in sufficient quantity for a wide range of consumers. The application of automated farm equipments helps in improving the efficiency of the crop production as well as in decreasing the labour cost. Decrease in total cost of production, cutback in time and reduction in the effort involved in the agricultural process is the resultant outcome. The aim of the project is to develop multipurpose automated farm equipment that can perform operations like ploughing, seed dispensing and spraying water or pesticides. This equipment is battery operated and is controlled by a smart phone. The equipment also provides manual control when necessary and is controlled using IoT (Internet of Things). The smart phone keeps a farmer updated about ongoing conditions on his agricultural land using IoT at any time and place. IoT can downgrade the cost and labour related problems and improve the productivity of conventional farming. Implementing this farm equipment in the agriculture field can assist farmers in the preliminary stages of agriculture i.e. ploughing, seed dispensing, pesticide and water spraying. This equipment is helpful for farmers who are interested to continue conventional agricultural activity, with improved output.

KEYWORDS: Automation; Farm Equipment; Internet of Things; Multipurpose
\end{abstract}

Received: Jun 08, 2020; Accepted: Jun 28, 2020; Published: Sep 01, 2020; Paper Id.: IJMPERDJUN20201005

\section{INTRODUCTION}

In the existing scenario, every process is being automated and people are adopting smart techniques to get their dayto-day work done. The conventional methods of farming and ever diminishing farm labour availability are making agriculture economically impracticable and unproductive. Regarding the above, research on development of smart autonomous machinery for carrying agricultural activities is essential to improve the productivity of the agricultural produce [1].It is observed that with passage of time seed sowing technology have kept on progressing. However, water and pesticide spraying are also important agricultural processes. Despite agriculture being one of the prominent sectors in determining the economic growth of a country, it is found short in terms of smart working. If advanced technology is initiated in farming techniques there is every chance that the growing world population in the coming future might be fed adequately. To cater to the needs of such a large population, agricultural yield must also be increased enormously. Due to poor seed quality, inefficient farming practices and lack of cold storage facilities, an adequate amount of the farmer's produce is wasted. It is observed in practice that automation helps in increasing output of farming. In US, where advanced automation techniques in agricultural farming are implemented, it is observed that the cereal yield in US is nearly three times more than the yield in India. These figures clearly indicate that there is enormous need for introducing automation techniques in farming because, if appropriate measures are not taken at the right time, even though presently many countries have adequate stock of food to suffice its population, a time may come when the food stock may be inadequate to feed the entire population. In the existing scenario there is every need to harness the advanced technologies in order to get benefitted. 
Extensive research has been carried out on the automation of agri-systems. Almost all the research work was done on designing the automated equipments which majority focuses on enhancing the modern techniques of farming. AditiKokate and PriyankaYadav [1] developed a multipurpose agricultural robot working on solar energy. Arduino was used to supervise the entire process. Soil sensors were used for monitoring the environmental condition. It checks moisture level and alerts the farmer, then slowly pours required amount of water to the planted seeds in all the rows of the farming plot. Nithya, Lalitha Shree, Kiruthika and Krishnaveni [2] developed a smart garbage monitoring system suitable for Indian conditions. The proposed system enables the officials to schedule the clearing of all the bins in the locality by estimating a route map for traversal. This drastically reduces the manpower, fuel and difficulty in navigation. Sheikh MohdShahidMohdSadik and H.A. Hussain [3] designed and fabricated a multipurpose farming machine which can do applied simultaneously for ploughing, seed dispensing, irrigation and carrying or transporting goods. The machine was tested on field and found to reduce crop production time considerably. ChetanPatil, Vishal Deshmukh, ShaileshDeshmukh, GovindRai, ParagBute [4] designed and fabricated a robot that can effectively perform operations like automatic ploughing, seed dispensing and pesticide spraying. It also provides manual control when necessary and keeps check on humidity using humidity sensors. Initially the robot ploughs the entire field and proceeds to dispense seeds. S.S. Katariya, S.S. Gundal, Kanawade M.T and Khan Mazhar [5] developed a solar automated agricultural tracking system for fruit cropping that facilitates free movement in required path. The equipment is fully automated to save resources and also improves productivity. Dhatchanamoorthy, J. Arunkumar, P. Dinesh Kumar, K. Jagadeesh and P. Madhavan [6] developed a multipurpose agricultural vehicle, for performing agricultural operations like ploughing and seed dispensing. The design of the plough is modified to withstand heavy loads. Hariharr C Punjabi, SanketAgarwal, VivekKhithani, VenkateshMuddaliar and MrugendraVasmatkar [7] developed a new concept of farming using networks that updates farmers about the conditions of their farm on their smart phones. D. Swati Sambare and S.S. Belsare [8] developed a control mechanism to reduce efforts of farmers that drops seeds at required positions with adequate distance between seeds during seed dispensing. Sheikh Mohd Shahid Mohd Sadik [9] designed and fabricated farming equipment that can do multiple operations simultaneously. The machine was found to reduce ploughing time by $62.5 \%$ and seed sowing time by $66 \%$ when compared to the traditional method. D. Ramesh and H.P. Girishkumar [10] made a study on agricultural seed sowing equipments and they suggested that usage of innovative and advanced seed sowing equipments improve the efficiency of farming and in-turn reduce time and labour cost. Hiroyuki Takeshima and L. Patrick [11] studied the process of agricultural mechanization and concluded that agricultural mechanizationis a key economic characteristic of agricultural production systems. GholapDipakDattatraya et.al [12] developed a robotic agricultural machine that can sow seeds and also detect obstacles present in the path of the vehicle by infraredsensor.

The main objective of this work is to develop automated farm equipment that can accomplish operations like ploughing, seed dispensing and watering or pesticide spraying on agricultural fields. The other objectives are to 1) develop an effective and low cost automated agricultural system 2) facilitate the farmer to command the equipment conveniently from anyplace using IoT technology 3 ) enable the farmers to perform significant amount of work in minimum time.

\section{DESIGN METHODOLOGY}

The proposed work is focused on the development of low cost multipurpose farm equipment that can perform operations like ploughing, seed dispensing and watering or pesticide spraying on agricultural fields. The block diagram of the planned model is as shown in Figure 1. The system through microprocessor links to the hotspot as specified in the code. As the 
command $\mathrm{ON}$ is initiated through smart phone to controller, the motor starts and the motion is transmitted to front wheel through belt and pulley drive. As the equipment is in motion, the front wheel drives the seed distributer and the seeds in the hopper are dispensed into the soil at regular intervals. Similarly the pump is also activated for spraying water or pesticides as and when required.

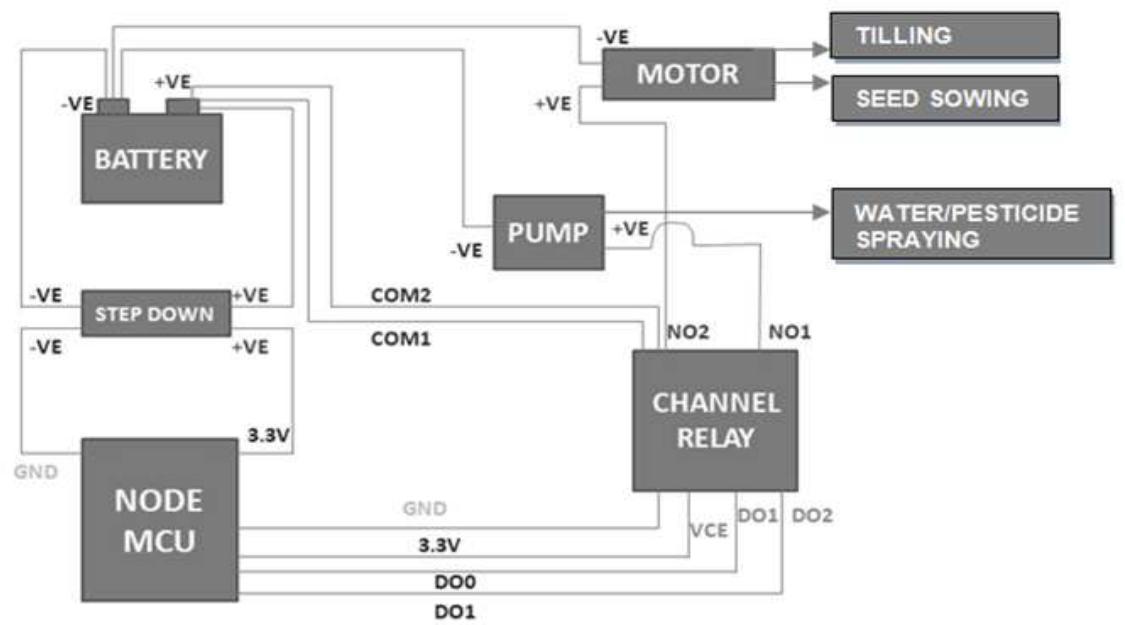

Figure 1: Block Diagram of Proposed Model.

\section{Factors that Influenced Design and Fabrication of Proposed Equipment}

- To implement scientific farming methods

- $\quad$ To bring precision in farming activities

- Suitability for all types and sizes of seeds to be sown

- Portability of the equipment: the proposed equipment to be of less weight and be flexible for easy assembly and disassembly.

- To provide low cost equipment for farmers.

\section{Components used in the Equipment}

The multipurpose automated agricultural equipment is fabricated using the components listed below. The specifications of the equipment are shown in Table 1.

- Frame - It is the structure on which the other components a built. It bears the entire load of the equipment

- Cultivator- Tills the soil to the required depth so the distributer mechanism can sow the seed.

- Belt and pulley drive- For transmission of power from motor to wheels; belt and pulley drive is used in the machine and also to drive seed distributer.

- Storage Tank- Stores water to be sprinkled in the soil and also pesticides for crops.

- Hopper - Stores the seeds to be sown in the soil. Higher the capacity less the need to refill the hopper during process.

- $\quad$ Pump- Used to pump the water or pesticide from tank to the sprinkler nozzle. 
- Seed Distributor - Consists of fluted rollers driven with the help of belt and pulley.

- D.C. Motor - Used to drive the front wheel which further drives the distributer.

Table 1: Specifications of the Equipment

\begin{tabular}{|l|l|}
\hline \multicolumn{1}{|c|}{ Parameters } & \multicolumn{1}{c|}{ Specifications } \\
\hline \multirow{2}{*}{ Frame } & Length: $610 \mathrm{~mm}$ \\
\cline { 2 - 2 } & Width: $356 \mathrm{~mm}$ \\
\cline { 2 - 2 } & Height: $254 \mathrm{~mm}$ \\
\hline Power transmission & Belt and pulley \\
\hline Hopper limit & 1kg of seeds \\
\hline Seeder & Length: $235 \mathrm{~mm}$; Diameter:40 mm \\
\hline \multirow{2}{*}{ Cultivator } & Height: $650 \mathrm{~mm} ;$ \\
\cline { 2 - 2 } & Width: $165 \mathrm{~mm}$ \\
\hline Number of distributer rollers & 2 \\
\hline Distribution mechanism \&driver & Fluted roller \& front wheel drive \\
\hline DC motor & 12 V DC \\
\hline
\end{tabular}

\section{Software design of Multipurpose Automated Agricultural Equipment}

CATIA software is used for modeling and assembling the different parts of the machine. CATIA is a solid modeling tool that integrates the 3D parametric features with 2D tools. The multipurpose automated agricultural equipment was modeled on these two main criteria. The first criterion is to keep the equipment design as simple as possible and to maintain low weight of the frame by reducing the number of pulleys used. The Figures 2, 3 and 4 illustrate the different views of the planned model.

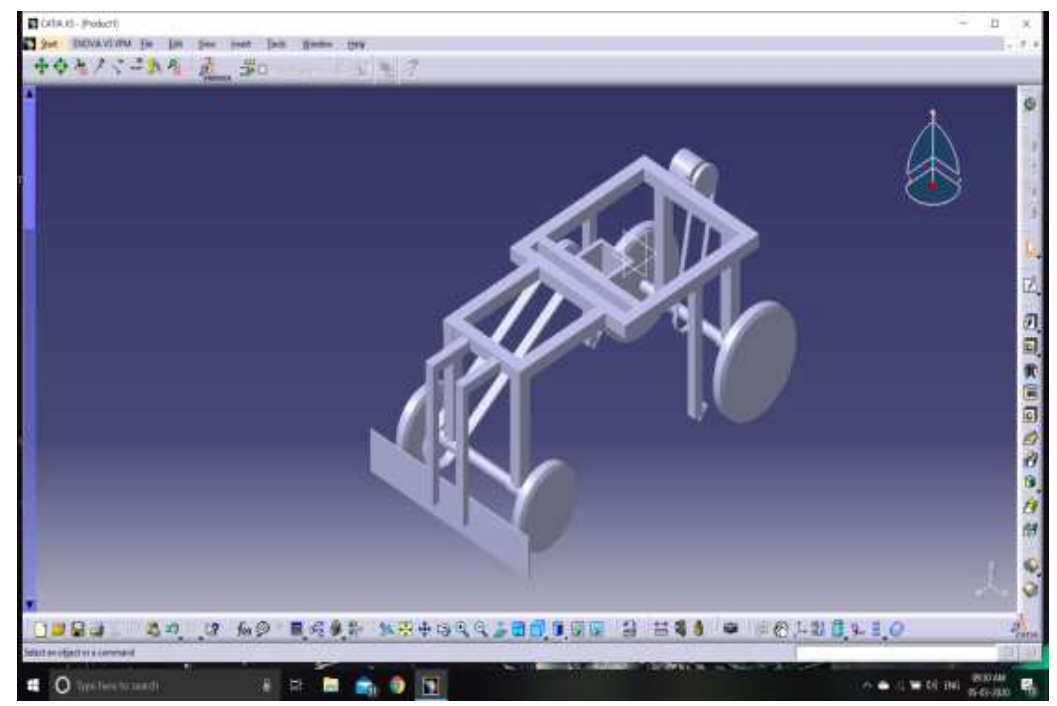

Figure 2: Proposed Model-Overview. 


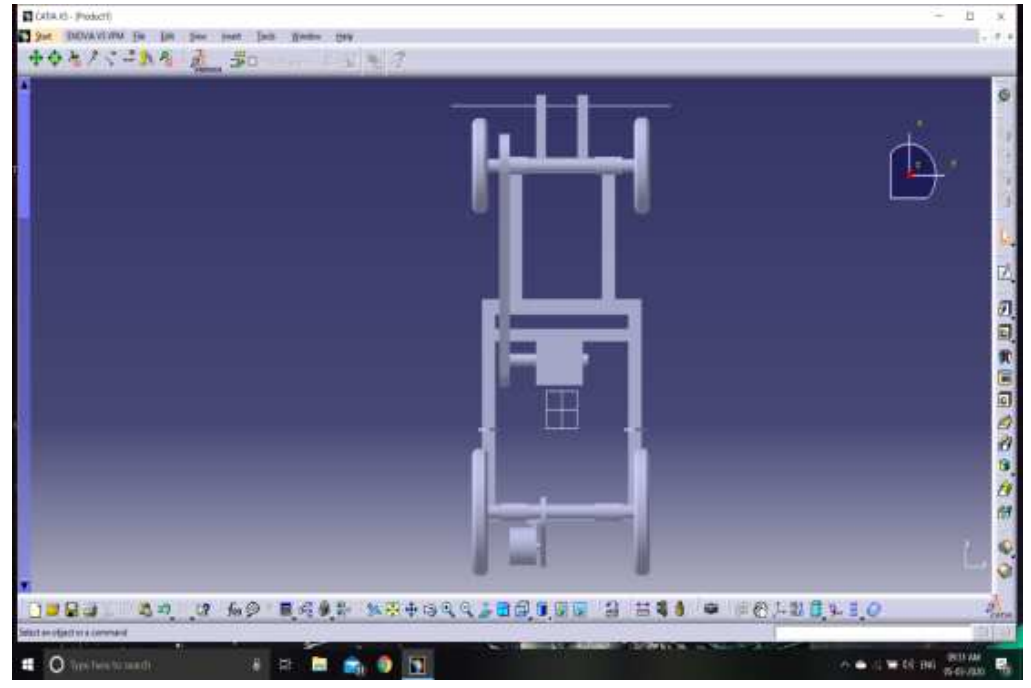

Figure 3: Proposed Model - Top View.

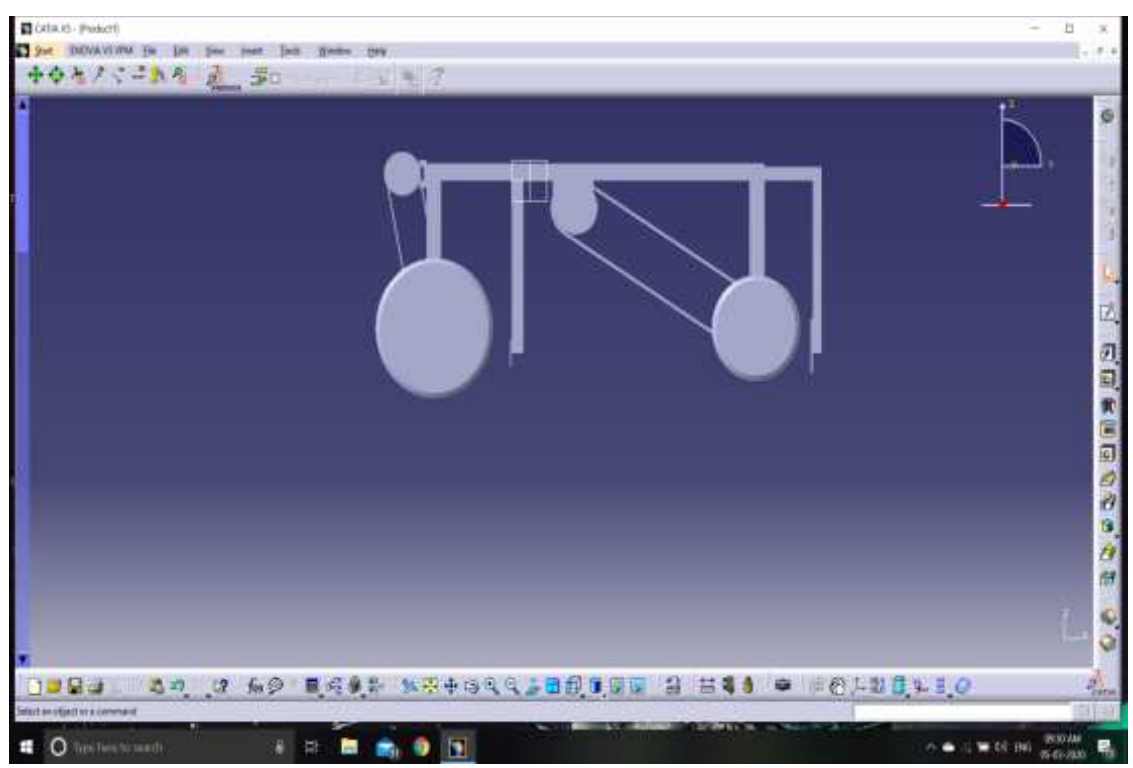

Figure 4: Proposed Model - Side View.

\section{Working Model}

Based on the design, all the components of the equipment are fabricated with suitable materials and are assembled accordingly. Figure 5 illustrates the working model of the equipment. The hopper made of mild steel has a seed storage capacity of two kilograms. A hopper is a funnel-shaped device used to feed seeds into the soil. The seed distributor shown is used to dispense seeds at regular intervals during sowing. It consists of two fluted rollers. These are driven using front wheels assisted by belt and pulley drive, and are mounted at the bottom of the hopper. Since two fluted rollers are used in this seed distributor, two seeds fall at a time on the ground. The distance between the two seeds would be approximately 12-14 inches. The cultivator ploughs the soil to the depth required so that seeds can be dispensed properly into the soil. The cultivator is fixed to adjustable knobs that can increase or decrease its height according to the requirement. The depth of the soil to be tilled varies with the type of crop to be grown. A motor with the pulley and a v-belt is connected to the front wheels. This motor is used to drive the front wheels. 


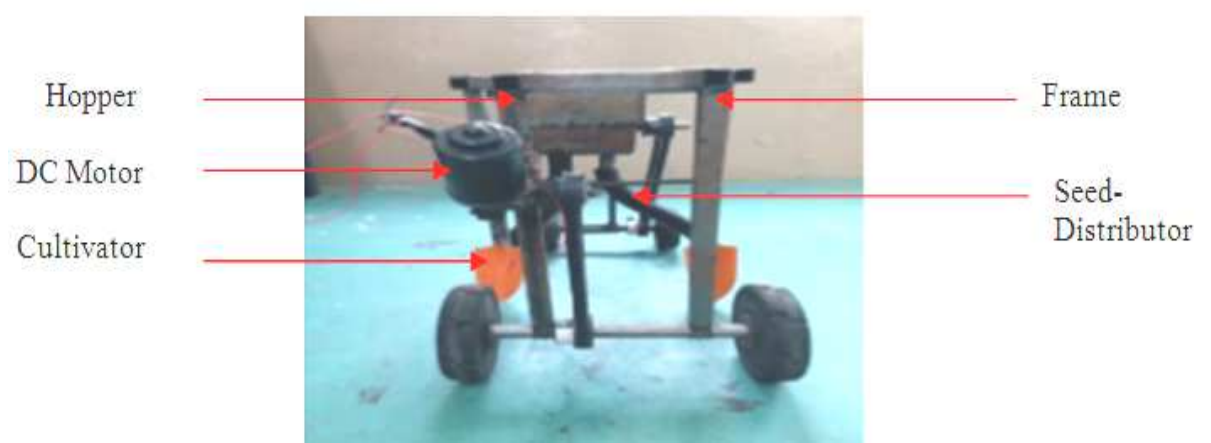

Figure 5: Working Model of the Automated Farm Equipment.

\section{CONCLUSIONS}

Automated agricultural machinery can handle farm related jobs in efficient and sophisticated manner. Digital solutions in combination with artificial intelligence and IoT can aid farmers in providing them with modern and sustainable agriculture to meet the challenges posed to food production in the 21 st Century. Implementing the automated farm equipment in agriculture, can assist the farmers in the initial stages of agriculture i.e. ploughing, seed dispensing, pesticide and water spraying.

- $\quad$ The automated farming equipment has adequate potential to enhance productivity of crops.

- The equipment is designed and fabricated as a multipurpose farming equipment which will do multiple operations simultaneously i.e. ploughing, seeding and water/pesticide spraying.

- The farm equipment has been successfully tested on field and is found to reduce ploughing time by $45 \%$ and seed sowing and water spraying time by $50 \%$ in contrast to conventional methods.

- Fewer manpower is required to run this equipment i.e. 1 person to operate. Therefore, the cost of production is less.

This machine is affordable even to small farmers at an approximate cost of Rs. 15000 and can readily be made from local components in workshops.

\section{REFERENCES}

1. Aditi D. Kokate and Priyanka D. Yadav (2007), “Multipurpose Agricultural Robot,” International Advance Research Journal in Science, Engineering and Technology, 4, (pp-97-99).

2. S. Nithya, Lalitha Shree, Kiruthika and Krishnaveni (2017), "Solar Based Smart Garbage Monitoring System Using IOT," International Journal of Electronics and Communication Engineering and Technology, 8, (pp-75-80).

3. Sheikh Mohd Shahid MohdSadik and Hussain H.A. (2017), "Design and Fabrication of Multipurpose Farming Machine," International Journal for Science and Advance research in Technology, 3, (pp-35-48).

4. ChetanPatil, Vishal Deshmukh, ShaileshDeshmukh and GovindRai, ParagBute (2018), "Design and Fabrication of Multipurpose Agro System,” International Journal of Current Engineering and Scientific Research, 5, (pp-73-79).

5. S.S. Katariya, GundalS.S., KanawadeM.T. and Khan Mazhar, “Automation in Agriculture,” International Journal of Recent Scientific Research,6, (pp-4453-4456). 
6. DhatchanamoorthyN., ArunkumarJ., Dinesh KumarP.,JagadeeshK. and MadhavanP., "Design and Fabrication of Multipurpose Agriculture Vehicle,"International Journal of Engineering Science and Computing, 8,(pp-17553-17560).

7. Hariharr C Punjabi, SanketAgarwal, VivekKhithani, VenkateshMuddaliarandMrugendraVasmatkar, "Smart Farming Using IoT, "International Journal of Electronics and Communication Engineering and Technology,8,(pp-58-66).

8. Swati SambareD. and BelsareS.S., “Seed Sowing Using Robotics Technology,” International Journal of Scientific Research and Management, 3, (pp-2889-2892).

9. PrathyushaShobila and Venkanna Mood (2015), “Automated Irrigation System Using Robotics and Sensors,” International Journal of Scientific Engineering and Research, 3, (pp-9-13).

10. RameshD. and GirishkumarH.P. (2014), “Agriculture Seed Sowing Equipments: A Review,” International Journal of Science, Engineering and Technology Research, 3, (pp-1987-1992).

11. Hiroyuki Takeshima and Patrick L. (2019), "Effects of agricultural mechanization on economies of scope in crop production in Nigeria," Agricultural Systems, 177, (pp-1-12).

12. Gholap DipakDattatraya, More VaibhavMhatardev, LokhandeManojkumarShrihari and JoshiS.G. (2014), "Robotic Agriculture Machine, "International Journal of Innovative Research in Science, Engineering and Technology, 3, (pp-454-462).

13. SakhaleC.N. and WaghmareN. (2016), “Multipurpose Farm Machine,” International Research Journal of Engineering Technology, 3, (pp-990-995).

14. HongkunTian, TianhaiWang, Yadong Liu, XiQiao and Yanzhou Li (2020), "Computer vision technology in agricultural automation-A review," Information Processing in Agriculture, 7, (pp-1-19).

15. Irshad Ali Mari, ChangyingJi, Farman Ali Chandio, ChuadryArslan, AsmaSattar and Fiaz Ahmad (2015), "Spatial distribution of soil forces on moldboard plough and draft requirement operated in silty-clay paddy field soil,"Journal of Terramechanics, 60, (pp-1-9).

16. Gandhi, F., Patel, H., Gohil, M., \& Singh, R. (2015). Advanced Instrumentation and Automation For Filling and Packaging of Beverages. International Journal of Electrical and Electronics Engineering Research (IJEEER), 5(1), 1-10.

17. Naik, U. (2016). Library Automation Software: A Comparative Study of Koha, Libsys, Newgenlib and Soul. International Journal of Library Science and Research (IJLSR), 6(6), 77-86.

18. Rajasekaran, P., Vanangamudi, S., \& Naveenchandran, P. Automation of Hydraulic Tyre Wear Testing Machine Using Proportional Control Valve by Interfacing Programming Logic Circuit.

19. Chowdary, U. V., Rohith, K., Sandeep, P., \& Ramu, M. (2015). Home automation system using IR sensors. International Journal of Electrical and Electronics Engineering, 4(6), 11-1. 

